https://doi.org/10.5800/GT-2017-8-3-0294

\title{
SHORT EPISODES OF CRUST GENERATION DURING PROTRACTED ACCRETIONARY PROCESSES: EVIDENCE FROM CENTRAL ASIAN OROGENIC BELT, NW CHINA
}

\author{
Gong-Jian Tang1, 2, Sun-Lin Chung3, Chris J. Hawkesworth4, 5, P. A. Cawood ${ }^{4,6}$, \\ Qiang Wang1, 2, Derek A. Wyman7 , Yi-Gang Xu1 ${ }^{1}$, Zhen-Hua Zhao' \\ ${ }^{1}$ State Key Laboratory of Isotope Geochemistry, Guangzhou Institute of Geochemistry, \\ Chinese Academy of Sciences, Guangzhou 510640, China \\ ${ }^{2}$ CAS Center for Excellence in Tibetan Plateau Earth Sciences (CETES), Beijing, China \\ ${ }^{3}$ Department of Geosciences, National Taiwan University, Taipei, Taiwan, China \\ ${ }^{4}$ Department of Earth Sciences, University of St. Andrews, St. Andrews Fife KY16 9AL, United Kingdom \\ ${ }^{5}$ Department of Earth Sciences, University of Bristol, Bristol BS8 1RJ, United Kingdom \\ ${ }^{6}$ School of Earth, Atmosphere \& Environment, Monash University, Melbourne, VIC 3800, Australia \\ ${ }^{7}$ School of Geosciences, The University of Sydney, Sydney, NSW 2006, Australia
}

For citation: Tang G.-J., Chung S.-L., Hawkesworth C.J., Cawood P.A., Wang Q., Wyman D.A., Xu Y.-G., Zhao Z.-H., 2017. Short episodes of crust generation during protracted accretionary processes: evidence from Central Asian Orogenic Belt, NW China. Geodynamics \& Tectonophysics 8 (3), 573-574. doi:10.5800/GT-2017-8-3-0294.

Accretionary orogens are major sites of generation of continental crust but the spatial and temporal distribution of crust generation within individual orogens remains poorly constrained. Paleozoic $(\sim 540-270 \mathrm{Ma})$ granitic rocks from the Alati, Junggar and Chinese Tianshan segments of the Central Asian Orogenic Belt (CAOB) have markedly bimodal age frequency distribu- tions with peaks of ages at $\sim 400 \mathrm{Ma}$ and $280 \mathrm{Ma}$ for the Altai segment, and $\sim 430 \mathrm{Ma}$ and $300 \mathrm{Ma}$ for the Junggar and Chinese Tianshan segments. Most of the magma was generated in short time intervals $(\sim 20-40 \mathrm{Ma})$, and variations in magma volumes and in $\mathrm{Nd}-\mathrm{Hf}$ isotope ratios are taken to reflect variable rates of new crust generation within a long-lived convergent plate setting. 
The Junggar segment is characterised by high and uniform $\mathrm{Nd}$-Hf isotope ratios $\left(\varepsilon_{\mathrm{Nd}}(\mathrm{t})=+5 \ldots+8\right.$; zircon $\left.\varepsilon_{\mathrm{Hf}}(\mathrm{t})=+10 \ldots+16\right)$ and it appears to have formed in an intra-oceanic arc system. In the Altai and Chinese Tianshan segments, the $\mathrm{Nd}-\mathrm{Hf}$ isotope ratios $\left(\varepsilon_{\mathrm{Nd}}(\mathrm{t})=\right.$ $=-7 \ldots+8$; zircon $\left.\varepsilon_{\mathrm{Hf}}(\mathrm{t})=-16 \ldots+16\right)$ are lower, although they increase with decreasing age of the rock units. The introduction of a juvenile component into the Chinese Tianshan and Altai granitic rocks appears to have occurred in continental arc settings and it reflects a progressive reduction in the contributions from old continental lower crust and lithospheric mantle. Within the long-lived convergent margin setting (over $\sim 200 \mathrm{Ma}$ ), higher volumes of magma, and greater contributions of juvenile material, were typically emplaced over short time intervals of $\sim 20-40 \mathrm{Ma}$. These intervals were associated with higher $\mathrm{Nb} / \mathrm{La}$ ratios, coupled with lower $\mathrm{La} / \mathrm{Yb}$ ratios, in both the mafic and granitic rocks, and these episodes of increased magmatism from intraplate-like sources are therefore thought to have been in response to lithospheric extension. The trace element and $\mathrm{Nd}-\mathrm{Hf}$ isotope data, in combination with estimates of granitic magma volumes, highlight that crust generation rates are strongly non-uniform within long-lived accretionary orogens. The estimated crust generation rates range from $\sim 0.1$ to $\sim 40 \mathrm{~km}^{3} / \mathrm{km} / \mathrm{Ma}$ for the Paleozoic record of the CAOB, and only comparatively short (20-40 Ma) periods of elevated magmatic activity had rates similar to those for modern intraoceanic and continental arcs. 